\title{
Influence of free carbon on the Young's modulus and hardness of polymer- derived silicon oxycarbide glasses
}

\author{
Gian Domenico Sorarù, Lakshminath Kundanati, Balanand Santhosh, Nicola Pugno
}

\begin{abstract}
Silicon oxycarbide (SiOC) glasses in the form of thin, dense, and crack-free samples were fabricated according to the polymer pyrolysis route starting from cross- linked polysiloxane. The amount of free carbon in the final SiOC materials was varied in the range $18-60$ vol\%. The mechanical properties of the SiOC glasses were measured by nanoindentaion technique and revealed that both the Young's modulus and the hardness decrease with increase in the free carbon content and follow a simple rule of mixtures model.
\end{abstract}

\section{1 | INTRODUCTION}

The anionic modification of silica glass with trifunctional $\mathrm{N}$ and tetrafunctional $\mathrm{C}$ atoms leads to the formation of silicon oxynitride, and silicon oxycarbide (SiOC), glasses. In both cases the substitution of divalent $\mathrm{O}$ atoms with a trivalent $\mathrm{N}$ or tetravalent $\mathrm{C}$ atoms increases the network connectivity with a corresponding increase in viscosity, elastic modulus, and hardness.1-3 Contrary to the oxynitrides, which are formed by a homogeneous amorphous network and are generally obtained from melting, SiOCs are produced through a pyrolysis process and have a more complex nanostructure consisting of a disordered SiOC network and a free carbon phase.4-6 The disordered network is built-up by mixed Si units sharing bonds simultaneously with $\mathrm{O}$ and $\mathrm{C}$ atoms and can be described by the formula: $\mathrm{SiCxO2}(1-\mathrm{x}), 0 \leq \mathrm{x} \leq 1$ in which " $x$ " is the amount of substituted $C$. Accordingly, the composition of the SiOC glasses is usually reported as: $\mathrm{SiCxO2}(1-\mathrm{x})+\mathrm{yCfree}$. 7,8 A sketch of the SiOC nanostructure is shown in Figure 1. The properties of SiOC glasses depend on both the amount of substituted carbon, that is, the " $x$ " value in the $\mathrm{SiCxO2}(1-x)$ formula, and the amount " $y$ " of free carbon with respect to each SiOC composition. For example, SiOC glasses with negligible amount of free carbon, that is, $y=0$, are transparent to visible light9 and behave as electrical insulators 10 while those with $\mathrm{y}>0$ are black and their electrical conductivity increases with increasing the free carbon content.11,12 In our earlier study, the mechanical properties such as Young's modulus (E) and the hardness $(\mathrm{H})$ of SiOC glasses (without free carbon, ie, $\mathrm{y}=0$ ) were reported as a function of the substituted $\mathrm{C}$, and we found that both the properties increase with the amount of $\mathrm{C}$ bonded to $\mathrm{Si}$, which was in agreement with the expectations based on topological considerations.13 In particular, the Young's modulus increases up to $110 \pm 6 \mathrm{GPa}$ (Esilica glass $=70 \mathrm{GPa}$ ) and the hardness up to $9.3 \pm 0.4 \mathrm{GPa}$ (HVsilica glass $=6 \mathrm{GPa}$ ) for a material with a composition SiC0.3701.25 and $y \approx 0$. On the other hand, the role of free carbon on the mechanical properties of SiOC glasses has not yet been reported in the literature and this could be of significant importance for many potential technological applications. For example, when the SiOCs are used as anodes for lithium ion batteries14,15 the volume expansion/contraction associated to the charging/discharging cycles can result in mechanical damage, which is dependent on the Young's modulus of the anodic materials. Indeed, it has 
been observed that the charging/discharging capacity of C-poor SiOCs degrades faster with the number of cycles than the C-rich SiOCs. This phenomenon has been tentatively ascribed to a lower elastic modulus of C-rich samples compared with C-poor ones, without Young's modulus measurements of the samples.16 In this study, we investigate the variation in the elastic modulus and the hardness of polymer-derived SiOC glasses from C-poor to C-rich samples. As the properties of SiOC glasses are also dependent on the amount

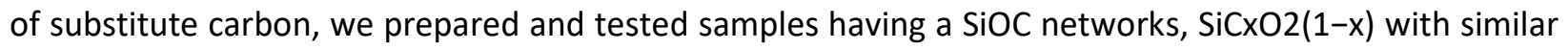
composition.

\section{2 | EXPERIMENTAL}

\section{1 | Synthesis of the samples}

The preceramic samples were obtained by crosslinking a linear siloxane containing $\mathrm{Si}-\mathrm{H}$ moieties with a vinyl-containing crosslinker via a platinum-catalyzed hydrosilylation reaction.17 Poly(hydridomethylsiloxane) (PHMS, MW 1900, CAS Number: 63148-57-2; Gelest, Morrisville, PA), 1,3,5,7-tetravinyl-1,3,5,7-tetramethylcyclotetrasiloxane (TVTMS, MW 345, CAS Number: CAS No: 255406-5; Gelest), and divinylbenzene (DVB, CAS: 1321-74-0; Sigma-Aldrich, St. Louis, MO) were used as received. Platinum divinyltetramethyldisiloxane complex, $\sim$ Pt $2 \%$ in xylene (CAS number: 68478-92-2; Sigma-Aldrich) was further diluted to $0.1 \%$ before using. The reagents, PHMS, TVTMS or DVB and the Pt catalyst (always $100 \mu \mathrm{L}$ for $1 \mathrm{~g}$ of PHMS) were mixed and stirred for 5 minutes before pouring the liquid on a Mylard film and letting it for setting. Accordingly, transparent polymeric films with a thickness in the range 100-200 $\mu \mathrm{m}$ were obtained and cut into discs of $\sim 10 \mathrm{~mm}$ in diameter. The preceramic films were pyrolyzed in $\mathrm{Ar}$ flow $(200 \mathrm{~cm} 3 / \mathrm{min})$ up to $1200^{\circ} \mathrm{C}$ with 1 hour holding time using an alumina tubular furnace (Lindberg/Blue, Asheville, NC). SiOC samples with low amount of free carbon were obtained by crosslinking PHMS with TVTMS while for C-rich composition PHMS was crosslinked with DVB (Table 1). C and Si contents of the SiOC films were analyzed by Mikroanalytisches Labor Pascher (Remagen-Bandorf, Germany). Carbon was analyzed based on combustion techniques while silicon was measured using inductively coupled plasma atomic emission spectroscopy. Oxygen was evaluated as difference to $100 \%$. Bulk density was measured with the Archimede method in distilled water. N2 physisorption measurements were performed with an ASAP 2010 Micromeritics instrument (Micromeritics, Norcross, GA). Scanning Electron Microscopy (SEM) pictures were taken from freshly fracture surfaces previously coated with a thin gold film using a JEOL JSM 5500 (JEOL, Tokyo, Japan) equipment operating at 10-15 kV.

\section{2 | Nanoindentation tests}

Silicon oxycarbide glass thin films obtained from the pyrolysis process were not perfectly flat and smooth enough to obtain reliable nanoindentation data. Thus, the samples were embedded in resin and polished using diamond suspensions down to $0.25 \mu \mathrm{m}$ particle size, to obtain flat and low roughness mirror finished surface. The samples blocks were fixed on the aluminum stubs that are inserted in to the sample holder of the nanoindenation machine (iNano; Nanomechanics, Inc, nanomechanics, Oak Ridge, TN). Tests were performed at two different locations on each sample surface to accommodate for possible heterogeneities across the surface and 12 indentations in an array $4 \times 3$ (with a spacing of $20 \mu \mathrm{m}$ in each direction) were performed at each location. The indentations were performed using a Berkovich indenter and a load of $40 \mathrm{mN}$. The reduced modulus of the samples was estimated using the software that is based on the standard procedure described in Oliver-Pharr.18 The Poisson ratio of the studied SiOC glasses, 
which is required to estimate the Young's modulus according to the Oliver-Pharr model, is not available in literature. However, Poisson ratios of silica glass and of a SiOC glass having a composition of SiC0.201.6 +0.6 Cfree are reported to be 0.15 and 0.11 , respectively.3,19 Consequently, we used an average value of Poisson ratio of 0.13 in the calculation of Young's modulus. It is worth mentioning that a \pm 0.02 difference in the Poisson ratio would change the corresponding Young's modulus values $<1 \%$.

\section{3 | RESULTS AND DISCUSSION}

Figure 2 shows the typical cured resin samples and the corresponding SiOC glass obtained after pyrolysis at $1200^{\circ} \mathrm{C}$ in N2 flow. After pyrolysis the samples showed shrinkage in the range $22 \%-29 \%$ depending on the amount of TVTMS or DVB used in the synthesis (Table 2). The samples obtained using TVTMS as crosslinker, containing the lowest amount of free carbon after pyrolysis, were the ones which showed the highest tendency to crack. In contrast, the samples with high amount of DVB lead easily to un- cracked, monolithic SiOC discs. The microstructural features of the SiOC samples were investigated by SEM. Accordingly, the SiOC samples have been fractured and the fracture surfaces were examined in search for a possible presence of porosity. SEM images reported in Figure 3 refer to SiOC- 1 and SiOC-4 samples, however, they are representative of all the studied materials. The SEM investigation reveals a dense, porefree glass with a typical glassy fracture surface and characteristic twist hackle features. In order to investigate the presence of smaller, micro-meso-pores a N2 physisorption analysis was also performed which showed, for all samples, flat adsorption/desorption isotherms typical of non-porous materials therefore confirming the formation of dense, pore-free SiOC glasses. Table 2 reports the bulk density, pyrolysis shrinkage, and the results of chemical analysis measured on the SiOC glass samples. In the same table the composition of the $\mathrm{SiOC}$ glasses is also reported as $\mathrm{SiCxO2}(1-\mathrm{x})+\mathrm{yCfree}$ together with the vol\% of the two components. In order to express the composition of the SiOC samples as vol\% of the $\mathrm{SiCxO2}(1-\mathrm{x})$ amorphous network and of the Cfree, the density of the two phases has to be estimated. In the literature, the density of $\mathrm{SiCxO2}(1-x)$ glassy phase with $\mathrm{x}=0.37$ has been reported in the range 2.3 $2.4 \mathrm{~g} / \mathrm{cm} 313,20$ while for pyrolythic carbon obtained from a phenol formaldehyde resin pyrolyzed at $1000^{\circ} \mathrm{C}$ the reported density is $1.45-1.55 \mathrm{~g} / \mathrm{cm} 3.21,22$ Accordingly, we decided to estimate the vol\% of the two phases assuming density values for the amorphous SiOC and Cfree as 2.35 and $1.5 \mathrm{~g} / \mathrm{cm} 3$,

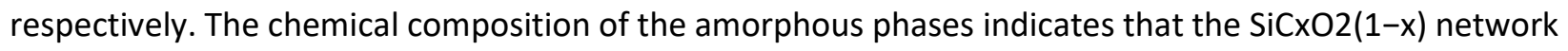
in the studied samples has similar $\mathrm{C}$ content in the range $\sim 0.4-0.5$ while the free carbon content spans from a minimum of $\sim 18$ vol\% up to a maximum of $\sim 60$ vol\%. Typical force-depth curves from the nanoindentation were reported and they showed good repeatability (Figure 4$)$. The results also show that with a load of $40 \mathrm{mN}$, the observed depth of penetration is in the order of $\sim 0.5 \mu \mathrm{m}$. The Young's modulus and the hardness values obtained from the nanoindentation experiments are reported in Table 3 and plotted in Figure 5 as a function of the vol \% of free carbon present in each sample. Note that in the fits of Figure 4 we are neglecting the influences of the amount of carbon bonded to silicon, that is, the $x$ value in the $\mathrm{SiCxO2}(1-\mathrm{x})$ formula, on $\mathrm{E}$ and $\mathrm{H}$ due to its limited range (0.38-0.5). Moreover, in the literature there are no data reporting the elastic modulus and hardness of SiOC glasses having similar compositions. The most important result, which clearly emerges from the nanoindentation data, is that both, the elastic modulus and the hardness decrease with increase in the volumetric fraction of free carbon. In both the cases these two properties show a linear relationship with the vol\% of free carbon suggesting that the nanocomposite follows reasonably well a simple rule of mixtures. By extrapolating the linear fit to zero percent of free carbon, the Young's modulus of the "pure" SiCxO2(1-x) $x=\sim 0.4-0.5$ is found to be $\sim 117$ 
GPa, in good agreement with the Young's modulus values measured on SiOC glasses with negligible amount of free carbon and $x=0.37 .13$ The same fit extrapolated to $100 \%$ free carbon estimates an elastic modulus value of the free carbon phase $\sim 63 \mathrm{GPa}$ which is higher than the value reported for carbon materials derived from pyrolysis of organic resins, which is $\sim 40 \mathrm{GPa} .21,23$ The lower elastic modulus that the high-C samples display compared with the low-C ones could help in rationalizing the experimental evidence of the lower tendency to crack during pyrolysis shown by the high-C samples. Similar experimental evidence was also reported on C-rich SiC derived from polycarbosilane.12 Accordingly, we consider that cracks during pyrolysis are generated from the development of stresses related to nonuniform shrinkage of the samples and they are proportional to the elastic modulus. Because the elastic modulus of the high-C content $\mathrm{SiOC}$ is up to $35 \%$ lower than the low-C content $\mathrm{SiOC}$, it is reasonable to suggest that the high- $\mathrm{C}$ samples can be more easily pyrolyzed into a crack-free component due to their lower elastic modulus which prevents the formation of high stresses. Extrapolation of the hardness fit to zero and $100 \%$ free carbon leads to values of 12.1 and $6 \mathrm{GPa}$, respectively. While the estimated value for the SiOC glass without free carbon $(12.1 \mathrm{GPa})$ is slightly above the typical values reported in the literature $(\sim 10 \mathrm{GPa})$, the hardness of the free carbon phase matched closely with the reported values $(\mathrm{H}=5.5-6.0$ $\mathrm{GPa} 23)$. We have observed that the $\mathrm{E} / \mathrm{H}$ ratio is $\sim 10$ for all the SiOC compositions, independently from the amount of free $\mathrm{C}$. According to Rouxel,24 glasses with $\mathrm{E} / \mathrm{H}=10$ and with Poisson ratio lower than 0.19 should behave, under Vickers indentation, as "anomalous glasses" like silica with the formation of $\mathrm{ring} /$ cone cracks instead of the radial/median cracks which forms in "normal" soda-lime glasses. In an earlier study, it was reported that pure $\mathrm{SiCxO2}(1-x)$ glasses with $\mathrm{y} \approx 0$ show anomalous behavior, that is, formation of Hertzian cone cracks during Vickers indentation, for low amount of substituted carbon and low pyrolysis temperature, while increasing these two parameters induce the transition from anomalous to normal behavior.20 The study of the Vickers indentation of SiOC glasses as a function of the free carbon content will be the subject of a next research.

\section{4 | CONCLUSIONS}

Silicon oxycarbide glasses with increasing amount of free C, from 18 up to 60 vol\%, have been synthesized in the form of thin, dense SiOC films and characterized by nanoindentation to evaluate the Young's modulus and the hardness. Our results show that both the elastic modulus and the hardness decrease with increase in the free carbon content and they followed a simple rule of mixtures. In particular the elastic modulus decrease linearly from 106 to 80 GPa when the C-free content increases from 18 vol\% to 60 vol\%. In the same Cfree content range the hardness decreased from $\sim 11$ to $\sim 8 \mathrm{GPa}$.

\section{ACKNOWLEDGMENTS}

G. D. Sorarù acknowledges the generous financial support of Fondazione Cassa di Risparmio di Trento e Rovereto under the contract: Polymer-derived ceramics with hierarchical porosity for water filtration/purification (project number 2015.0174). NMP is supported by the European Commission under the Graphene Flagship Core2 No. 785219 (WP14 “Polymer Composites") and FET Proactive "Neurofibres" grant No. 732344. N.M.P and L.K. are supported by Fondazione Caritro under "Self-Cleaning Glasses" No. 2016.0278. 


\section{REFERENCES}

1. Renlund GM, Prochazka S, Doremus RH. Silicon oxycarbide glasses: Part II. Structure and properties. J Mater Res. 1991;6:2723-34.

2. Hampshire S. Oxynitride glasses, their properties and crystallisation -a review. J Non-Cryst Sol. 2003;316:64-73.

3. Rouxel T. Elastic properties and short-to medium-range order in glasses. J Am Ceram Soc. 2007;90:3019-39.

4. Saha A, Raj R, Williamson DL. A model for the nanodomains in polymer-derived SiCO. J Am Ceram Soc. 2006;89:2188-95.

5. Widgeon SJ, Sen S, Mera G, Ionescu E, Riedel R, Navrotsky A. 29Si and 13C solid-state NMR spectroscopic study of nanometer-scale structure and mass fractal characteristics of amorphous polymer derived silicon oxycarbide ceramics. Chem Mater. 2010;22: 6221-8.

6. Soraru GD, Pena-Alonso R, Kleebe H-J. The effect of annealing at $1400^{\circ} \mathrm{C}$ on the structural evolution of porous C-rich silicon (boron)oxycarbide glass. J Eur Ceram Soc. 2012;32:1751-7.

7. Sorarù GD, D'Andrea G, Campostrini R, Babonneau F, Mariotto G. Structural characterization and high temperature behaviour of silicon oxycarbide glasses prepared from sol-gel precursors containing $\mathrm{Si}-\mathrm{H}$ bonds. J Am Ceram Soc. 1995;78:379-87.

8. Stabler C, Reitz A, Stein P, Albert B, Riedel R, lonescu E. Thermal properties of SiOC glasses and glass ceramics at elevated temperatures. Materials. 2018;11:279.

9. Dirè $S$, Borovin E, Narisawa M, Sorarù GD. Synthesis and characterization of the first transparent silicon oxycarbide aerogel obtained through H2 decarbonization. J Mater Chem A. 2015;3:24405-13.

10. Colombo P, Mera G, Riedel R, Sorarù GD. Polymer-derived ceramics: 40 years of research and innovation in advanced ceramics. J Am Ceram Soc. 2010;93:1805-37.

11. Cordelair G, Greil P. Electrical conductivity measurements as a microprobe for structure transitions in polysiloxane derived Si-O- C ceramics. J Eur Ceram Soc. 2000;20:1947-57.

12. Dalcanale F, Grossenbacher J, Blugan G, Gullo MR, Lauria A, Brugger J, et al. Influence of carbon enrichment on electrical conductivity and processing of polycarbosilane derived ceramic for MEMS applications. J Am Ceram Soc. 2014;34:3559-70.

13. Sorarù GD, Dallapiccola E, D'Andrea G. Mechanical characterization of sol-gel-derived silicon oxycarbide glasses. J Am Ceram Soc. 1996;79:2074-80.

14. Fukui H, Harimoto $Y$, Akasaka M, Eguchi K. Lithium species in electrochemically lithiated and delithiated silicon oxycarbides. ACS Appl Mater Interfaces. 2014;6:12827-36.

15. Graczyk-Zajac M, Vrankovic D, Waleska P, Hess C, Sasikumar PV, Lauterbach S, et al. The Li-storage capacity of SiOC glasses with and without mixed silicon oxycarbide bonds. J Mater Chem A. 2018;6:93103. 
16. Pradeep VS, Graczyk-Zajac M, Riedel R. New insights in to the lithium storage mechanism in polymer derived SiOC anode materials. Electrochim Acta. 2014;119:78-85.

17. Blum Y, Sorarù GD, Ramaswamy AP, Hui D, Carturan SM. Controlled mesoporosity in SiOC via chemically bonded polymeric "spacers". J Am Ceram Soc. 2013;96:2785-92.

18. Oliver WC, Pharr GM. An improved technique for determining hardness and elastic modulus using load and displacement sensing indentation experiments. J Mater Res. 1992;7: 1564-83.

19. Moysan C, Riedel R, Harshe R, Tanguy Rouxel, Augereau F. Mechanical characterization of a polysiloxane-derived SiOC glass. J Eur Ceram Soc. 2007;27:397-403.

20. Walter S, Soraru GD, Brequel H, Enzo S. Microstructural and mechanical characterization of sol gelderived SiOC glasses. J Eur Ceram Soc. 2002;22:2389-400.

21. Šupová M, Svítilová J, Chlup Z, Cerny M, Weishauptova Z, Suchy T, et al. Relation between mechanical properties and pyrolysis temperature of phenol formaldehyde resin for gas separation membranes. Ceram - Silikáty. 2012;56:40-9.

22. Ko T-H, Kuo W-S, Chang Y-H. Microstructural changes of phenolic resin during pyrolysis. J Appl Polym Sci. 2001;81: 1084-9.

23. Jurkiewicz K, Pawlyta M, Zygadło D, Chrobak D, Duber S, Wrzalik R, et al. Evolution of glassy carbon under heat treatment: correlation structure-mechanical properties. J Mater Sci. 2018;53:3509-23.

24. Rouxel T. Driving force for indentation cracking in glass: composition, pressure and temperature dependence. Phil Trans R Soc A. 2015;373:20140140.

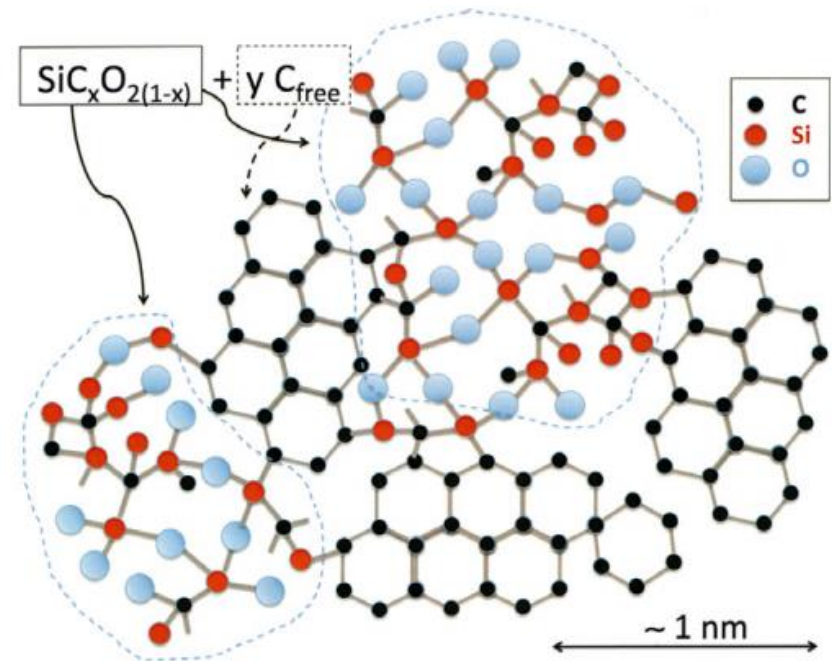

FIGURE 1 Sketch of the nanostructure of silicon oxycarbide glasses showing the amorphous $\mathrm{SiC}_{x} \mathrm{O}_{2(1-x)}$ network and the free carbon phase 
TABLE 1 Composition of the starting precursors

\begin{tabular}{llll} 
Sample & PHMS (g) & TVTMS $(g)$ & DVB $(g)$ \\
SiOC-1 & 1 & 2 & - \\
\hline SiOC-2 & 2 & 5 & - \\
\hline SiOC-3 & 1 & - & 1 \\
\hline SiOC-4 & 1 & - & 2 \\
\hline SiOC-5 & 1 & - & 4 \\
\hline SiOC-6 & 1 & - & 6 \\
\hline
\end{tabular}

DVB, divinylbenzene; PHMS, poly(hydridomethylsiloxane); TVTMS, 1,3,5,7tetravinyl-1,3,5,7-tetramethylcyclotetrasiloxane.

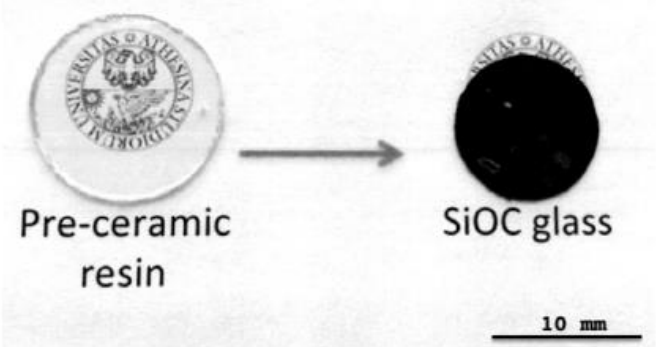

FIGURE 2 Typical samples in the "as cured state" and after conversion into the $\mathrm{SiOC}$ glass 

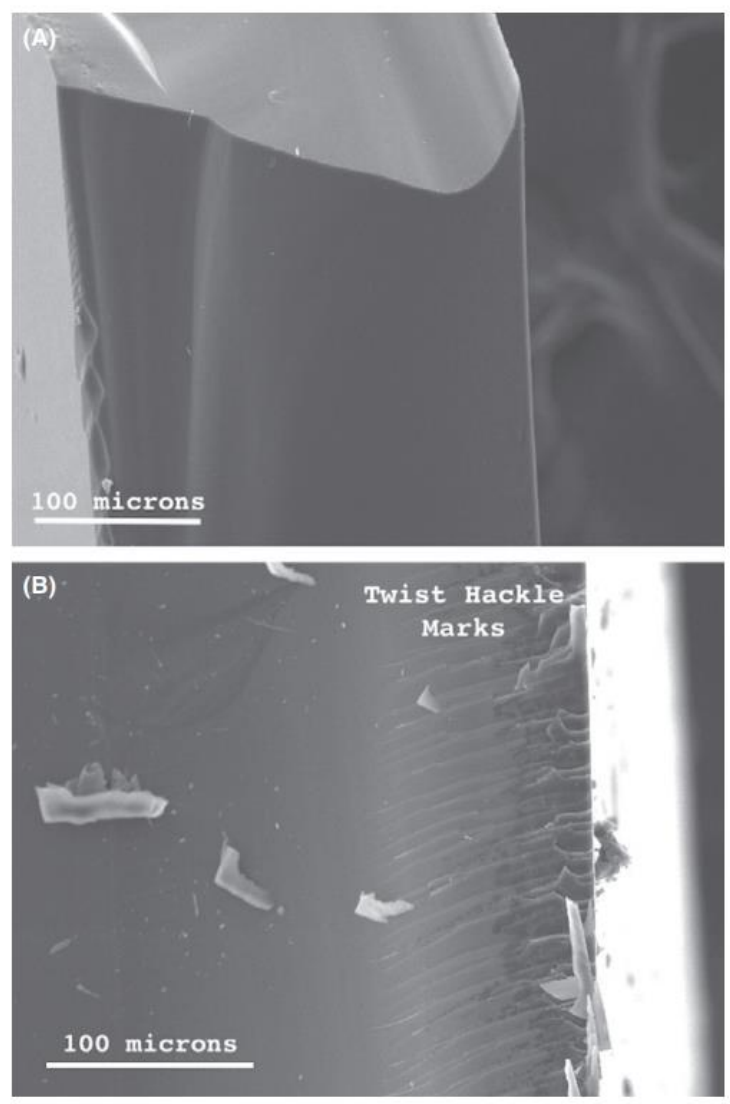

FIGURE 3 Scanning Electron Microscopy pictures of the fracture surface of (A) SiOC-1 and (B) SiOC-4 compositions showing the formation of dense, pore-free glasses. In (B) the twist hackle marks are clearly seen

TABLE 2 Chemical composition, bulk density, and pyrolysis shrinkage of the studied SiOC glasses

\begin{tabular}{|c|c|c|c|c|c|c|c|c|c|c|}
\hline \multirow[b]{2}{*}{ Sample } & \multirow{2}{*}{$\begin{array}{l}\text { Bulk density } \\
\left(\mathrm{g} / \mathrm{cm}^{3}\right)\end{array}$} & \multirow{2}{*}{$\begin{array}{l}\text { Shrinkage } \\
(\%)\end{array}$} & \multirow[b]{2}{*}{$\mathrm{Si}(\mathrm{wt} \%)$} & \multirow[b]{2}{*}{ C (wt\%) } & \multirow[b]{2}{*}{$O(w t \%)$} & \multirow{2}{*}{$\begin{array}{l}\text { Composition } \\
\mathrm{SiC}_{x} \mathrm{O}_{2(1-x)}+y \mathrm{C}_{\text {free }}\end{array}$} & \multicolumn{2}{|c|}{$\underline{\mathrm{SiC}_{x} \mathrm{O}_{2(1-x)}}$} & \multicolumn{2}{|l|}{${\underline{C_{\text {free }}}}$} \\
\hline & & & & & & & (wt\%) & (Vol. \%) & (wt\%) & (Vol\%) \\
\hline SiOC-1 & $2.32 \pm 0.1$ & $22 \pm 2$ & $46.8 \pm 0.1$ & $19.9 \pm 0.1$ & $33.4 \pm 0.2$ & $\mathrm{SiC}_{0.38} \mathrm{O}_{1.25}+0.61 \mathrm{C}$ & 87.8 & 82.1 & 12.2 & 17.9 \\
\hline $\mathrm{SiOC}-2$ & $2.16 \pm 0.1$ & $22 \pm 2$ & $46.9 \pm 0.1$ & $20.7 \pm 0.6$ & $32.5 \pm 0.7$ & $\mathrm{SiC}_{0.39} \mathrm{O}_{1.21}+0.63 \mathrm{C}$ & 87.7 & 82.0 & 12.3 & 18.0 \\
\hline $\mathrm{SiOC}-3$ & $1.95 \pm 0.1$ & $23 \pm 2$ & $38.4 \pm 0.2$ & $38.4 \pm 0.3$ & $23.3 \pm 0.2$ & $\mathrm{SiC}_{0.47} \mathrm{O}_{1.06}+1.87 \mathrm{C}$ & 69.4 & 59.1 & 30.6 & 40.9 \\
\hline $\mathrm{SiOC}-4$ & $1.83 \pm 0.1$ & $27 \pm 2$ & $33.2 \pm 0.1$ & $47.9 \pm 0.1$ & $18.9 \pm 0.1$ & $\mathrm{SiC}_{0.50} \mathrm{O}_{1.00}+2.86 \mathrm{C}$ & 59.3 & 48.2 & 40.7 & 51.8 \\
\hline SiOC-5 & $1.82 \pm 0.1$ & $29 \pm 2$ & $29.3 \pm 0.1$ & $51.0 \pm 0.1$ & $19.8 \pm 0.1$ & $\mathrm{SiC}_{0.41} \mathrm{O}_{1.18}+3.66 \mathrm{C}$ & 47.3 & 43.0 & 52.7 & 57.0 \\
\hline SiOC-6 & $1.82 \pm 0.1$ & $27 \pm 2$ & $28.4 \pm 0.1$ & $52.3 \pm 0.1$ & $19.4 \pm 0.1$ & $\mathrm{SiC}_{0.40} \mathrm{O}_{1.20}+3.90 \mathrm{C}$ & 45.8 & 41.5 & 54.2 & 58.5 \\
\hline
\end{tabular}

The vol\% of the amorphous $\mathrm{SiC}_{x} \mathrm{O}_{2(1-x)}$ and $\mathrm{C}$-free phases have been calculated assuming the density of the two phases as described in the text. 

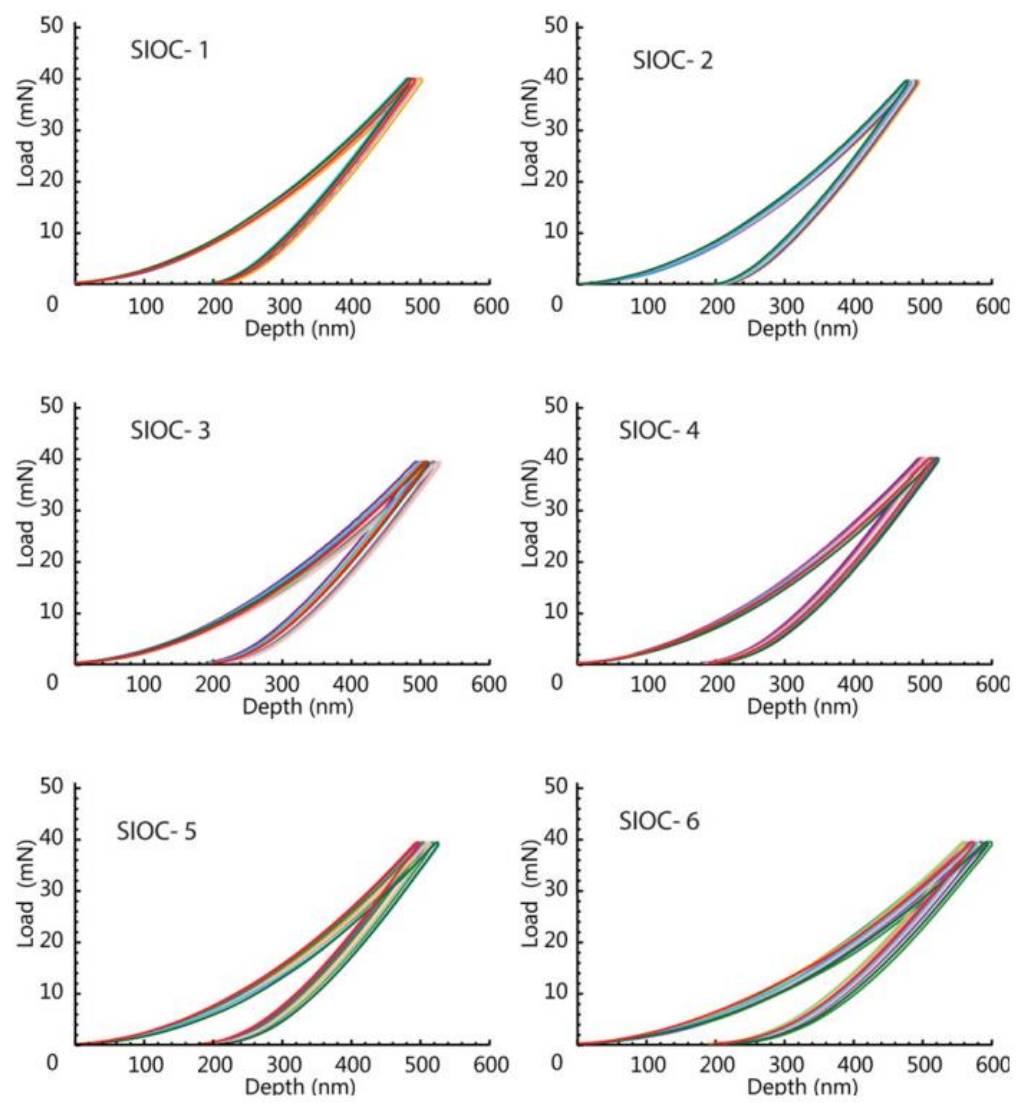

FIGURE 4 Typical force-depth curves from the indentation experiments of all the SiOC samples

TA B LE 3 Experimental Young's modulus and hardness values obtained from the nanoindentation tests

\begin{tabular}{|c|c|c|c|c|}
\hline Sample & Location & $\begin{array}{l}\text { Young's } \\
\text { modulus } \pm \text { STD } \\
(\text { GPa })\end{array}$ & $\begin{array}{l}\text { Hardness } \pm \text { STD } \\
(\text { GPa) }\end{array}$ & $E / H$ \\
\hline \multirow[t]{2}{*}{ SiOC-1 } & 1 & $107.9 \pm 4.4$ & $11.0 \pm 0.8$ & 9.8 \\
\hline & 2 & $105.7 \pm 6.2$ & $10.7 \pm 1.0$ & 9.9 \\
\hline \multirow[t]{2}{*}{ SiOC-2 } & 1 & $106.7 \pm 3.4$ & $10.8 \pm 0.5$ & 9.9 \\
\hline & 2 & $110.0 \pm 3.5$ & $11.3 \pm 0.9$ & 9.7 \\
\hline \multirow[t]{2}{*}{ SiOC-3 } & 1 & $95.8 \pm 5.2$ & $9.7 \pm 0.8$ & 9.9 \\
\hline & 2 & $92.9 \pm 5.1$ & $9.8 \pm 0.9$ & 9.5 \\
\hline \multirow[t]{2}{*}{ SiOC-4 } & 1 & $92.8 \pm 3.4$ & $9.4 \pm 0.5$ & 9.8 \\
\hline & 2 & $83.3 \pm 4.3$ & $8.6 \pm 0.9$ & 9.7 \\
\hline \multirow[t]{2}{*}{ SiOC-5 } & 1 & $93.3 \pm 5.2$ & $8.4 \pm 2.6$ & 9.8 \\
\hline & 2 & $88.5 \pm 5.3$ & $8.9 \pm 0.7$ & 10.2 \\
\hline \multirow[t]{2}{*}{ SiOC-6 } & 1 & $86.7 \pm 3.9$ & $8.8 \pm 0.6$ & 11.1 \\
\hline & 2 & $76.9 \pm 4.7$ & $7.5 \pm 0.8$ & 9.9 \\
\hline
\end{tabular}



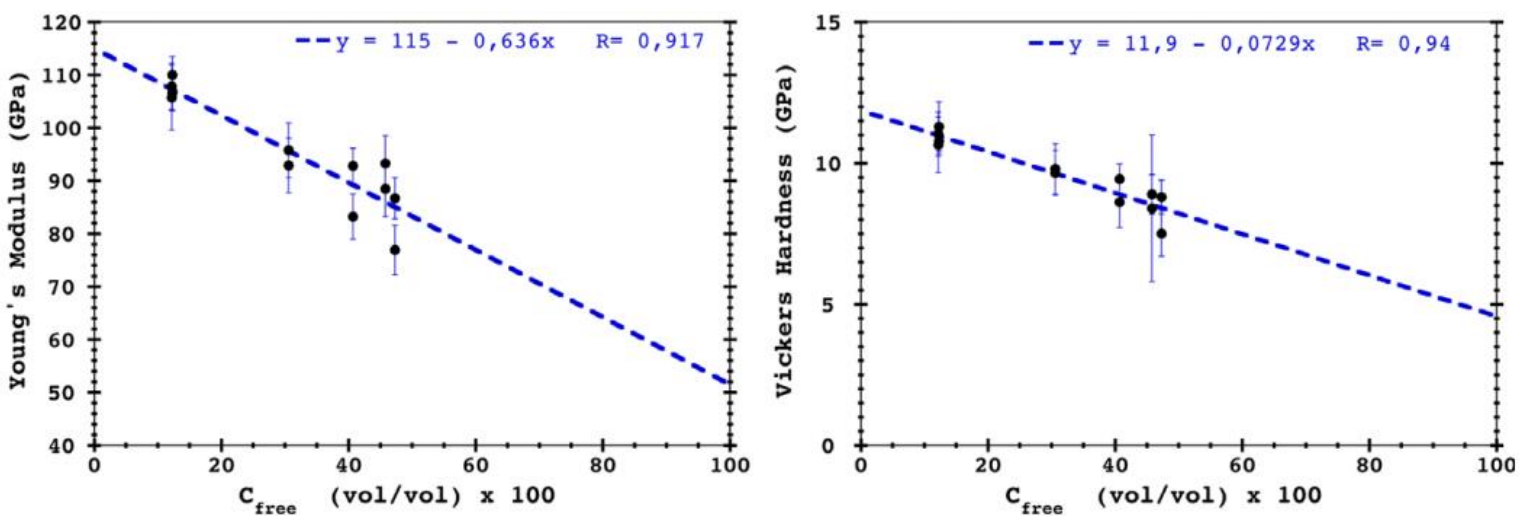

FIG URE 5 Plots of the Young's modulus and hardness as a function of the vol\% of $\mathrm{C}_{\text {free }}$ 